\title{
PRODUTIVIDADE, FENOLOGIA E MATURAÇÃO DA ‘CABERNET SAUVIGNON’ PARA DIFERENTES ÉPOCAS DE PODA
}

\section{YIELD, PHENOLOGY AND RIPENING OF ‘CABERNET SAUVIGNON’ GRAPEVINE FOR DIFFERENT PRUNING DATES}

\author{
Mário José Pedro Júnior ${ }^{1,2 *}$, José Luiz Hernandes ${ }^{1}$, Gabriel Constantino Blain ${ }^{1}$, \\ Ludmila Bardin-Camparotto ${ }^{1,3}$ \\ ${ }^{1}$ Instituto Agronômico (IAC/APTA/SAA), Avenida Barão de Itapura, 13001-970, CP 28, Campinas - São Paulo, Brasil. \\ ${ }^{2}$ Bolsista CNPq \\ ${ }^{3}$ Bolsista FAPESP \\ *corresponding author: Mário José Pedro Júnior, Instituto Agronômico (IAC/APTA/SAA), Avenida Barão de Itapura, 13001-970, CP 28, \\ Campinas - São Paulo, Brasil. e-mail: mpedro@iac.sp.gov.br
}

(Recebido em 07.05.2013. Aceite em 08.04.2014)

\section{RESUMO}

Devido à crescente importância de uvas finas para vinho no Estado de São Paulo foi feita a caracterização da fenologia, produtividade, curva de maturação e características químicas do mosto numa vinha de ‘Cabernet Sauvignon’ para diferentes épocas de poda na região de São Roque, SP. O delineamento experimental foi inteiramente casualizado com amostragem de trinta plantas e os valores médios das variáveis fitotécnicas e químicas do mosto foram comparados pelo teste 't'. As épocas de poda avaliadas foram 5/Ago; 6/Set; 22/Set e 19/Nov. A duração média do ciclo total da 'Cabernet Sauvignon' foi de 183 dias e a do período de maturação foi de 63 dias. A produtividade da 'Cabernet Sauvignon' diminuiu a partir da época de poda 5/8 (13,3 t.ha $\left.{ }^{-1}\right)$ até a de 19/11 (8,4 t.ha $\left.{ }^{-1}\right)$. O teor de sólidos solúveis (TSS) variou, para as diferentes épocas de poda, entre 18,7 e 19,9 $9^{\circ}$ Brix, enquanto os valores de acidez titulável total (ATT) ficaram entre os extremos de 96 e 111 meq.L ${ }^{-1}$. Foram desenvolvidas equações de estimativa do teor de sólidos solúveis e da acidez total em função de graus-dia acumulados a partir da data de floração. Os valores de produtividade, TSS e de ATT obtidos indicam ter a 'Cabernet Sauvignon’ potencial para utilização pelos viticultores visando produção de vinhos de qualidade na região.

\section{SUMMARY}

The increasing importance in producing fine grapes for wine purposes in the State of São Paulo (Brazil) induced the development of a field trial aiming to characterized phenology, yield, maturation curve and must chemical properties for the grapevine 'Cabernet Sauvignon' considering different pruning dates in the county of São Roque (São Paulo State, Brazil). The experimental design was completely randomized using a sample of thirty plants and the average values of agronomic parameters and must chemical variables were compared by the statistical ' $t$ ' test. The pruning dates evaluated were: Aug, $5^{\text {th }}$; Sept, $6^{\text {th }}$; Sept, $22^{\text {nd }}$ and Nov, $19^{\text {th }}$. The average cycle length for the 'Cabernet Sauvignon' grapevine was 182 days while the ripening period lasted 63 days. The yield decreased from the pruning date Aug, $5^{\text {th }}\left(13.3\right.$ t.ha $\left.{ }^{-1}\right)$ to Nov, $19^{\text {th }}$ ( 8.4 t.ha $\left.{ }^{-1}\right)$. The total soluble solids (TSS) varied for the different pruning dates from 18.7 to $19.9^{\circ}$ Brix, while the total titratable acidity (ATT) values varied from 96 to 111 meq. $\mathrm{L}^{-1}$. Equations were developed to estimate the TSS and ATT as a function of accumulated degree-days starting at the flowering date. According to the obtained values of yield, TSS and ATT it was verified the potential of 'Cabernet Sauvignon' for the growers aiming to produce better quality wines in the grape growing region of São Roque (São Paulo, Brazil).

Palavras-chave: produção, uva para vinho, teor em açúcar, graus-dia. Key words: yield, wine grape, sugar content, degree-day.

\section{INTRODUÇÃO}

A vitivinicultura do leste paulista tem se baseado na utilização de uvas rústicas para elaboração de vinhos. Recentemente, Verdi et al. (2011) verificaram que ações organizadas de diferentes entidades promoveram a atividade do agroturismo levando para a região consumidores mais exigentes em vinhos de qualidade. Em função desta atual demanda os viticultores têm mostrado interesse no cultivo de uvas finas para vinho, destacando-se a 'Cabernet Sauvignon' por ser muito difundida na maior parte dos países produtores de vinho (Rizzon e Miele,
2002) sendo dentre as uvas viníferas uma das mais cultivadas no Brasil.

A 'Cabernet Sauvignon' tem sido avaliada sob diferentes aspectos visando caracterizar seu desenvolvimento em diferentes regiões do país. Em relação à fenologia, Jubileu et al.(2010) determinaram para a 'Cabernet Sauvignon' produzida fora de época (safra de inverno) no norte do Paraná, duração do ciclo total de 128 dias. Também, Sato et al. (2011) relataram ciclo de 130 dias para a safra de verão em Maringá (PR). 
A avaliação do potencial desta cultivar em relação ao teor de sólidos solúveis (TSS) e à acidez titulável total (ATT) para diferentes regiões vitícolas também tem sido feita por vários autores no Brasil. No Rio Grande do Sul, Rizzon e Miele (2002) avaliaram a 'Cabernet Sauvignon', durante as safras de 1987 a 1992, tendo encontrado valores médios de teor de sólidos solúveis totais de $18,1^{\circ}$ Brix e ATT de 120 meq. ${ }^{-1}$. Mota et al. (2008) avaliaram o comportamento da 'Cabernet Sauvignon' sob cultivo protegido verificando que a cobertura plástica influiu no crescimento das videiras, porém não afetando a produção. Em Santa Catarina, Brighenti et al. (2011) mostraram que a cultivar em regiões de altitude elevada atinge valores de TSS entre 20,2 e 22,6 $6^{\circ}$ Brix e ATT de 77 a 100 meq. $L^{-1}$.

Sato et al. (2011), no Paraná, relataram valores de TSS de $14,5^{\circ}$ Brix em videiras conduzidas em latada, enquanto Detoni et al. (2007) em vinhedos conduzidos em espaldeira, sem e com cobertura de plástico, relataram valores de de $17,3^{\circ}$ Brix e ATT entre 87 e 114 meq.L ${ }^{-1}$. Também, Jubileu et al. (2010) no norte do Paraná, obtiveram elevados valores de TSS (19,2 ${ }^{\circ}$ Brix) para videiras podadas em janeiro e colhidas durante os meses de inverno. Por sua vez, na região cafeeira de Minas Gerais, Mota et al. (2010) avaliaram o potencial de maturação da 'Cabernet Sauvignon', durante o ciclo de primavera-verão, obtendo valores de TSS de $14,9^{\circ}$ Brix e ATT de 87 meq. $L^{-1}$.

No Estado de São Paulo, Ferreira et al.(2004) trabalhando com a 'Cabernet Sauvignon' em ambiente a céu aberto e parcialmente modificado (sob cobertura de plástico) relataram valores de TSS entre 13,7 e $15,0^{\circ}$ Brix, em função do porta-enxertos para a região de Jundiaí (SP). Mais tarde, Orlando et al. (2008) na mesma região obtiveram valores mais elevados de TSS (17 ${ }^{\circ}$ Brix) sendo a acidez total do mosto 145 meq. $\mathrm{L}^{-1}$. Recentemente, Regina et al. (2011) verificaram na região nordeste de São Paulo valores de TSS da ordem de 24 a $27^{\circ}$ Brix.

A obtenção de uvas com boa qualidade para vinificação e elevados teores sólidos solúveis nas diferentes regiões vitivinícolas do país, inclusive em São Paulo, induziram alguns produtores do município de São Roque a cultivarem a 'Cabernet Sauvignon' para elaboração de vinhos finos. Portanto, o objetivo deste trabalho foi caracterizar seu comportamento fenológico e produtivo; a variação dos parâmetros de qualidade ao longo do período de maturação; avaliar a composição química do mosto e obter relações do TSS e da acidez total com a acumulação de graus-dia.

\section{MATERIAL E MÉTODOS}

O ensaio foi conduzido em vinhedo comercial pertencente à Vinícola Góes localizada no município de São Roque (SP) e situada a $850 \mathrm{~m}$ de altitude, latitude $47^{\circ} 08^{\prime} \mathrm{W}$ e longitude $23^{\circ} 32^{\prime} \mathrm{S}$. O clima segundo Koeppen é Cfb e durante a fase de maturação das uvas a temperatura média mensal foi $22,5^{\circ} \mathrm{C}$ e 0 total de chuvas cerca de $400 \mathrm{~mm}$.

Foram utilizadas videiras (Vitis vinifera L.) 'Cabernet Sauvignon' enxertadas sobre Paulsen 1103, conduzidas em espaldeira com espaçamento de 1,2 m entre plantas e 2,7 m entre linhas com densidade aproximada de 3100 plantas.ha ${ }^{-1}$.

O delineamento experimental foi inteiramente casualizado e as podas curtas de inverno foram realizadas em: 5/8/11; 6/9/11; 22/9/11 e 19/11/11 tendo sido as colheitas obtidas, respectivamente, em: 01/02/2012, 07/03/2012, 25/03/2012 e 15/05/2012.

O acompanhamento da maturação da uva (amostragens quinzenais) foi feito por meio da coleta de 100 bagos que foram divididas em 4 subamostras para fins de análise química. Foram avaliados em cada amostra: teor de sólidos solúveis (TSS), em ${ }^{\circ}$ Brix, por meio de refratômetro ótico manual com escala de $0-32^{\circ}$ Brix; $\mathrm{pH}$, por meio de potenciómetro de bancada; acidez titulável total, realizada por titulação do suco com solução padronizada de $\mathrm{NaOH}$ $0,1 \mathrm{~N}$ tendo sido ajustado para $\mathrm{pH}=8,2$ como ponto final da titulação e o resultado expresso em meq. $\mathrm{L}^{-1}$.

Durante o período experimental foram obtidos valores diários de temperatura do ar e total de chuva com estação meteorológica automática da Campbell Scientific colocada no centro do vinhedo tendo sido o abrigo termométrico com sensor modelo HMP 45C instalado ao nível do coberto vegetal do vinhedo.

A caracterização dos subperíodos fenológicos foi feita avaliando-se a data de ocorrência de $50 \%$ das plantas nos seguintes estádios: floração, início da maturação e vindima.

Os valores de TSS e ATT obtidos durante a fase de maturação foram comparados aos graus-dia acumulados (temperatura base $=10^{\circ} \mathrm{C}$ ) por meio de análise de regressão para determinação do tipo de função que melhor se ajustava à distribuição dos dados.

Na época da colheita foi feita a contagem, em 30 plantas, do número de cachos e foram colhidos 30 cachos aleatoriamente para determinação da massa, comprimento e largura do cacho. A produção por planta foi estimada pelo número de cachos por planta e massa média dos cachos. Também foram separadas 100 bagos para análise de TSS, pH e ATT. Os valores médios das características fitotécnicas das videiras (produção e número de cachos); do cacho (peso, comprimento e largura) e do mosto (TSS, pH e ATT) foram submetidos a análise de variância e comparados pelo teste " $t$ " ao nível de $5 \%$ de significância.

\section{RESULTADOS E DISCUSSÃO}

Os resultados obtidos para a 'Cabernet Sauvignon' enxertada sobre Paulsen 1103 e conduzida em espaldeira são apresentados visando caracterizar: o 
comportamento fenológico e produtivo das plantas; a evolução da maturação, o mosto do ponto de vista físico-químico e suas relações com o acúmulo de graus-dia.

\section{Fenologia}

Na Figura 1 são apresentadas as durações dos subperíodos fenológicos observados para as diferentes datas de poda. Verificou-se que os valores de duração dos subperíodos avaliados não diferiram em função da data de poda e os valores médios foram: 53, 65 e 63 dias, respectivamente, para: poda-floração; floração-início da maturação e início da maturaçãocolheita. A duração do subperíodo início da maturação-colheita, obtida neste trabalho, foi mais longa que a observada por Jubileu et al. (2010) que variou entre 36 e 52 dias, em função do ano e da safra. A duração média do ciclo desde a poda até a colheita foi de 183 dias, variando entre os extremos de 178 (poda de 19/11) e 185 (poda de 22/9). Esses valores são muito próximos aos relatados por Borghesan et al. (2011), de 174 dias, em São Joaquim, SC. Por outro lado, são superiores aos relatados por Jubileu et al. (2010) e Sato et al. (2011) ambos para o Paraná, que observaram duração do ciclo total, respectivamente, de 128 e 130 dias. O ciclo mais longo, da poda à colheita, observado no presente trabalho pode ser consequência das condições climáticas locais e da realização da colheita da uva após a estabilização dos parâmetros de maturação, relativas ao TSS e ATT e pH, em valores superiores aos relatados por Sato et al. (2011). Por outro lado, Jubileu et al. (2010) obtiveram ciclo mais curto em função de produção da 'Cabernet Sauvignon’ em estação outonal, em que as condições climáticas reinantes proporcionaram redução da duração do ciclo da videira e melhores condições para maturação.

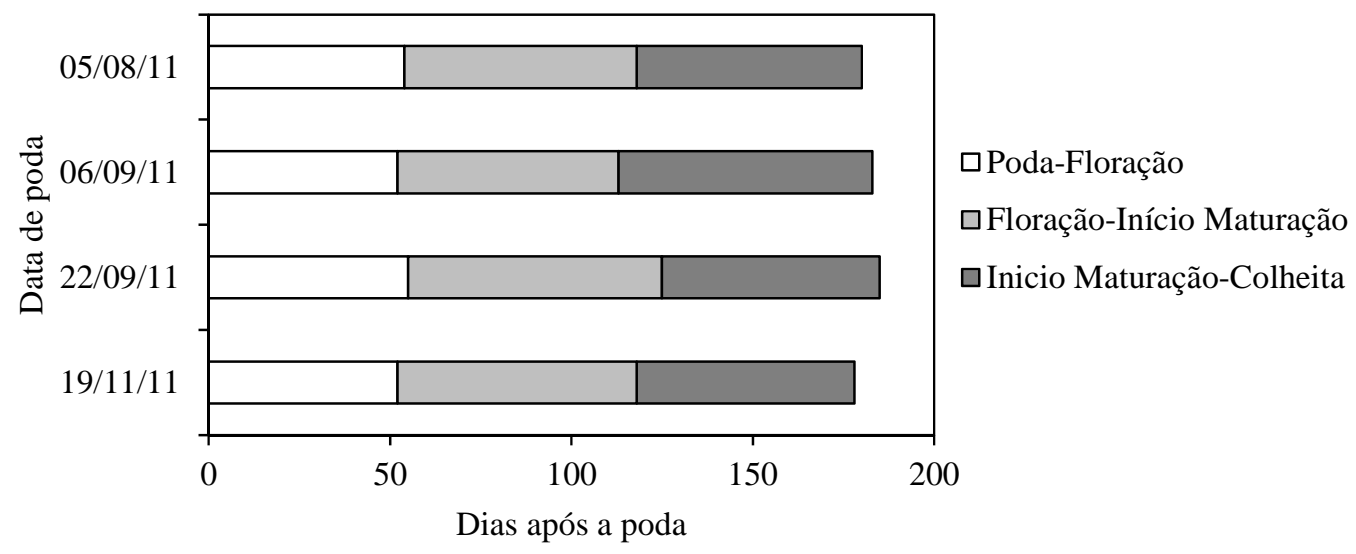

Figura 1. Fenologia da ‘Cabernet Sauvignon’ para diferentes datas de poda na região de São Roque, SP.

Phenology of 'Cabernet Sauvignon' for different pruning dates at São Roque, São Paulo State, Brazil.

\section{Características fitotécnicas}

No Quadro I são mostrados os valores médios de características dos cachos da 'Cabernet Sauvignon' conduzida em espaldeira para diferentes épocas de poda.

Em relação ao tamanho dos cachos foram observados maiores valores de comprimento $(15,7 \mathrm{~cm})$ para a poda efetuada em $5 / 8$, que diferiram estatisticamente das podas de 6/9 e 22/9 (respetivamente 14,1 e 13,5 $\mathrm{cm})$. Os menores valores $(11,9 \mathrm{~cm})$ foram observados para a poda de 19/11. No caso da avaliação da largura dos cachos não foi observada diferença estatística entre as podas de 5/8, 6/9 e 22/9, com valores em torno de 6,0 a 6,4 cm. Apenas para a poda de 19/11 foi encontrada diferença estatística para os valores (5,3 cm) quando comparadas às demais épocas de poda.

Foi observado que os maiores valores de peso dos cachos foram obtidos para as podas efetuadas em 5/8 (157,9 g) seguidos pelas efetuadas em 6/9 (138,0 g) e 22/9 (134,6 g). Tendo sido os menores valores observados para a poda de 19/11 (87,7g). Foi notada uma tendência de diminuição do valor médio da massa dos cachos quando as podas se afastaram do mês de agosto até o mês de novembro. Os valores de peso dos cachos obtidos na região de São Roque para a poda de 5/8 (157,9 g) são semelhantes aos relatados por Rizzon e Miele (2002) para o Rio grande do Sul e por Jubileu et al. (2010), enquanto os valores mais baixos obtidos para a época de poda de 19/11 (87,7 g) foram similares aos relatados por Sato et al. (2011) para o Paraná e Mota et al. (2008) para o Rio Grande do Sul em videiras conduzidas sob cobertura plástico. Essa diminuição na massa dos cachos pode ser explicada pelo desgaste das reservas da planta uma vez que com o retardamento da poda, as plantas sofrem uma brotação natural, principalmente nas extremidades dos ramos do ano anterior a partir de setembro, utilizando as reservas de amido uma vez que, para iniciar novo ciclo vegetativo, este é convertido em açúcares, que serão utilizados para nutrirem as novas brotações da videira (Giovannini, 1999; Bates et al., 2002). 


\section{QUADRO I}

Médias do peso, comprimento e largura dos cachos e produtividade da ‘Cabernet Sauvignon’ para diferentes datas de poda em São Roque, SP, durante o ano agrícola de 2011/12.

‘Cabernet Sauvignon’ mean values of cluster weight, width and length and yield for different pruning dates at São Roque, São Paulo State, Brazil, during the growing season of 2011/12.

\begin{tabular}{ccccc}
\hline $\begin{array}{c}\text { Data de } \\
\text { poda }\end{array}$ & $\begin{array}{c}\text { Peso do cacho } \\
(\mathbf{g})\end{array}$ & $\begin{array}{c}\text { Comprimento do cacho } \\
(\mathbf{c m})\end{array}$ & $\begin{array}{c}\text { Largura do cacho } \\
\mathbf{( \mathbf { c m } )}\end{array}$ & $\begin{array}{c}\text { Produtividade estimada } \\
\left(\mathbf{t . h a}^{-\mathbf{1}}\right)\end{array}$ \\
\hline $5 / 8$ & $157,9 \mathrm{a}$ & $15,7 \mathrm{a}$ & $6,2 \mathrm{a}$ & $13,31 \mathrm{a}$ \\
$6 / 9$ & $138,0 \mathrm{~b}$ & $14,1 \mathrm{~b}$ & $6,4 \mathrm{a}$ & $13,23 \mathrm{a}$ \\
$22 / 9$ & $134,6 \mathrm{~b}$ & $13,5 \mathrm{~b}$ & $6,0 \mathrm{a}$ & $11,10 \mathrm{~b}$ \\
$19 / 11$ & $87,7 \mathrm{c}$ & $11,9 \mathrm{c}$ & $5,3 \mathrm{~b}$ & $8,44 \mathrm{c}$ \\
\hline DMS & 17,13 & 1,37 & 0,48 & 1,91 \\
C.V. $(\%)$ & 19,6 & 14,6 & 12,1 & 17,7 \\
\hline
\end{tabular}

Médias seguidas da mesma letra nas colunas não diferem estatisticamente entre si ao nível de 5\% pelo teste 't'

Os valores de produtividade estimada para as épocas de $5 / 8$ e 6/9, cerca de 13,2 t.ha $^{-1}$, não diferiram estatisticamente entre si. Porém mostraram-se superiores, em valores médios, às observadas para as podas de 22/9 e a de 19/11. No Quadro I pode-se observar que os valores de produtividade estimada foram decrescentes em função da época de poda a partir do mês de agosto até novembro, influenciados principalmente pelo peso dos cachos. Os valores obtidos para as podas efetuadas em agosto e setembro foram superiores aos relatados por Ferreira et al. (2004), Orlando et al. (2008), Mota et al. (2010) e Sato et al. (2011). Alguns autores consideram que produtividades entre 5 e 7 t.ha $^{-1}$ são aceitáveis no cultivo de uvas destinadas à elaboração de vinho de qualidade (Mota et al., 2010). Os valores estatisticamente diferentes e mais baixos encontrados para a poda de 19/11, cerca de 8,4 t.ha ${ }^{-1}$, foram similares aos relatados para diferentes regiões do país que variaram entre 6 e 8 t.ha ${ }^{-1}$ (Orlando et al., 2008; Mota et al., 2010; Sato et al., 2011). As produtividades mais baixas observadas para a época de poda de 19/11 foram devidas, além do efeito dos componentes da produção, a uma maior dificuldade existente pelas condições climáticas de elevada umidade no controle das podridões que pode ter afetado os valores do peso dos cachos por queda antecipada de bagos.

Pelos valores obtidos de tamanho dos cachos e produtividade verificou-se terem sido as épocas de poda, relativas ao mês de agosto e início de setembro, mais favoráveis na região de São Roque (SP). Enquanto podas mais tardias, apesar de propiciarem produtividades mais baixas, ainda são comparáveis com as produtividades obtidas para a 'Cabernet Sauvigon’ em diferentes regiões do país.

\section{Características químicas do mosto}

No Quadro II são apresentados os valores de TSS, pH e acidez total para as diferentes épocas de poda da
'Cabernet Sauvignon’ na região de São Roque (SP). Os valores obtidos foram estatisticamente diferentes para as épocas de poda avaliadas em função de baixo valor do dms $(0,31)$. A maior diferença $\left(1,2^{\circ}\right.$ Brix) foi observada entre as podas de 22/9 (19,9 $9^{\circ}$ Brix) e de 19/11 (18,7 Brix). Esses valores foram superiores aos relatados para safra de verão por Orlando et al. (2008) para Jundiaí (SP), Mota et al. (2010) para Cordislândia (MG), Sato et al. (2011) para Maringá (PR) e similares aos apresentados por Jubileu et al. (2010) para Maringá (PR) para uvas produzidas na safra de inverno e Rizzon e Miele (2002) para Bento Gonçalves (RS) em safra de verão. Porém foram inferiores aos relatados por Regina et al. (2011) para a região nordeste de São Paulo em regime de dupla poda. Apesar de inferiores aos encontrados em outras regiões, os teores de sólidos solúveis obtidos são suficientes para elaboração de vinhos com graduação alcoólica entre 10 e $13^{\circ} \mathrm{GL}$, como determina a legislação brasileira, uma vez que, para a formação de cada $1^{\circ}$ GL de álcool, é necessário $1,8^{\circ}$ Brix no mosto.

Com relação ao pH os valores obtidos não diferiram estatisticamente entre si ficando entre os extremos de 3,22 a 3,27 tendo sido compatíveis aos relatados para outros estados do país e adequados à produção de vinho de uvas V. viniferas (Rizzon e Miele, 2002). Manfroi et al. (2004) obtiveram pH de 3,18 para 'Cabernet Franc', no RS, enquanto, Sato et al. (2011), obtiveram pH de 3,3 para 'Cabernet Sauvignon', no PR. A coloração das uvas tintas é influenciada pela acidez e pelo $\mathrm{pH}$. Em frutas com $\mathrm{pH}$ baixo a cor é vermelha e brilhante, desejável para vinhos tintos, enquanto $\mathrm{pH}$ elevado está relacionado com cor azulada e escura (Hidalgo, 2002).

A acidez titulável total (ATT) variou, em função da época de poda, entre 96 meq. $L^{-1}$ (poda de 22/9) a 111 meq. $\mathrm{L}^{-1}$ (poda de 5/8), correspondendo a valores de 


\section{QUADRO II}

Médias do teor de sólidos solúveis, pH e acidez titulável para o mosto de ‘Cabernet Sauvignon’ para diferentes datas de poda em São Roque, SP, durante o ano agrícola de 2011/2012.

'Cabernet Sauvignon' mean values of soluble solids, pH and titratable acidity for different pruning dates at São Roque, São Paulo State, Brazil, during the growing season of 2011/12.

\begin{tabular}{cccc}
\hline Data de poda & $\begin{array}{c}\text { Teor de sólidos solúveis } \\
\left({ }^{\circ} \text { Brix) }\right.\end{array}$ & pH & $\begin{array}{c}\text { Acidez titulável } \\
\text { (meq.L }{ }^{-\mathbf{1}} \text { ) }\end{array}$ \\
\hline $05 / 08 / 2011$ & $18,9 \mathrm{c}$ & $3,27 \mathrm{a}$ & $111 \mathrm{a}$ \\
$06 / 09 / 2011$ & $19,4 \mathrm{~b}$ & $3,24 \mathrm{a}$ & $99 \mathrm{~b}, \mathrm{c}$ \\
$22 / 09 / 2011$ & $19,9 \mathrm{a}$ & $3,27 \mathrm{a}$ & $96 \mathrm{c}$ \\
$19 / 11 / 2011$ & $18,7 \mathrm{c}$ & $3,22 \mathrm{a}$ & $105 \mathrm{a}, \mathrm{b}$ \\
\hline DMS & 0,31 & 0,06 & 7,49 \\
C.V. (\%) & 1,05 & 0,87 & 4,73 \\
\hline
\end{tabular}

Médias seguidas da mesma letra nas colunas não diferem estatisticamente entre si ao nível de 5\% pelo teste 't

ácido tartárico entre 0,72 e 0,83\%. Sato et al. (2011), obtiveram para a 'Cabernet Sauvignon' valores equivalentes a $1,1 \%$ no PR. Rizzon e Miele (2002) encontraram, para a 'Cabernet Sauvignon' cultivada na Serra Gaúcha, ATT de $0,85 \%$ ao final da maturação. Os valores de acidez total obtidos neste trabalho foram da mesma ordem de grandeza dos relatados por Jubileu et al. (2010) e superiores aos de Brighenti et al. (2011) para a 'Cabernet Sauvignon' no estado de Santa Catarina.

Os valores obtidos de TSS, pH e ATT para a 'Cabernet Sauvignon' em São Roque (SP) para a safra de verão, independentemente da data de poda, mostraram-se adequados e muito promissores para o viticultor regional que destina sua produção para a elaboração de vinho.

\section{Curva de maturação}

Na Figura 2 são mostradas as curvas de acumulação TSS para as diferentes épocas de poda e a variação diária da temperatura máxima e mínima do ar e da chuva. A taxa de acumulação de TSS observada foi: 0,202; 0,202; 0,163 e 0,195 ${ }^{\circ} \quad$ Brix.dia $^{-1}$, respectivamente para as podas efetuadas em 5/8, 6/9, 22/9 e 19/11. As colheitas das épocas de poda de 5/8 e de 6/9 foram efetuadas em fase de maior ocorrência de chuvas, fato este que pode ser prejudicial ao acúmulo do TSS. A influência negativa do excesso de chuvas sobre a maturação da uva pôde ser verificada em praticamente todas as épocas de poda, mas especialmente na fase final de maturação da poda de 6/9 em que ocorreu a estabilização e mesmo variação negativa de TSS nos últimos dois decêndios que precederam a colheita. Para as épocas de poda de 22/9 e 19/11 a colheita coincidiu com períodos de menor ocorrência de chuvas, mesmo assim esses valores não contribuíram para obtenção de maiores valores de TSS. A poda mais tardia de 19/11, quando se esperava colheita em período seco, também teve o acúmulo de TSS prejudicado pela maior quantidade de chuvas. Pode-se verificar, pela Figura 2, que para a época de poda de 19/11 os valores de TSS praticamente não evoluíram nos últimos decêndios que precederam a colheita, provavelmente em função da diminuição das temperaturas e maior frequência de ocorrência de chuvas.

\section{Comparação entre Graus-dia, TSS e ATT}

Na Figura 3 são apresentadas as comparações entre os valores de graus-dia acumulados a partir da data de floração e os valores de TSS e a ATT para a ‘Cabernet Sauvignon' para a safra de verão. Foi feita comparação considerando-se em conjunto os valores amostrais de TSS e ATT das diferentes datas de poda e apresentada a função que melhor se ajustou à distribuição dos dados em função do coeficiente de determinação. Tanto no caso da TSS quanto no da ATT a melhor função que se ajustou aos dados (Figura 3) foi do tipo:

$\mathrm{Y}=\mathrm{e}^{(\mathrm{a}+\mathrm{b} / \mathrm{x}+\mathrm{c} \operatorname{Ln} \mathrm{x})}$

onde: Y é a TSS ( ${ }^{\circ}$ Brix) ou ATT (meq.L ${ }^{-1}$ ); x é o número de graus-dia acumulados a partir do florescimento e a,b,c são coeficientes da equação. No Quadro III são apresentados os coeficientes das equações de estimativa e coeficientes de correlação.

No caso da estimativa do TSS foi obtido elevado coeficiente de correlação $(r=0,95)$ e na Figura 3 observa-se que a partir da acumulação de 1500 GD após a floração o TSS estabilizou em torno de 19,5 Brix. Em relação à acidez total após a acumulação do mesmo total de graus-dia ocorre uma tendência à estabilização em torno de 100 meq.L ${ }^{-1}$. As equações obtidas poderão servir de subsídio para avaliação do potencial da 'Cabernet Sauvignon' cultivada em safra de verão para diferentes regiões e principalmente para as que possuírem condições climáticas similares. 

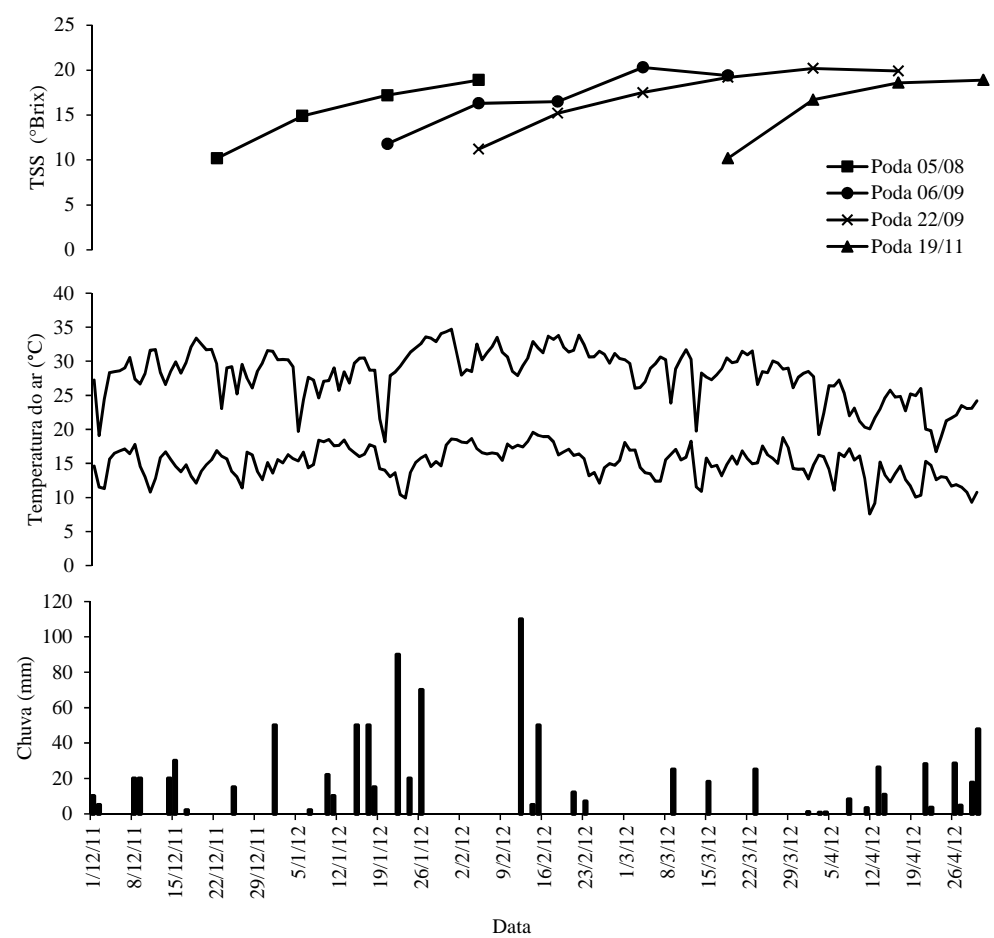

Figura 2. Variação do teor de sólidos solúveis (TSS) da ‘Cabernet Sauvignon’ para diferentes datas de poda, da temperatura do ar máxima e mínima e da chuva durante o período de 1/12/2011 a 30/04/2012 em São Roque, SP.

Variation of 'Cabernet Sauvignon' soluble solids for different pruning dates, daily maximum and minimum temperature and rainfall, during the period of 2011/12/1 to 2012/4/30, at São Roque São Paulo State, Brazil
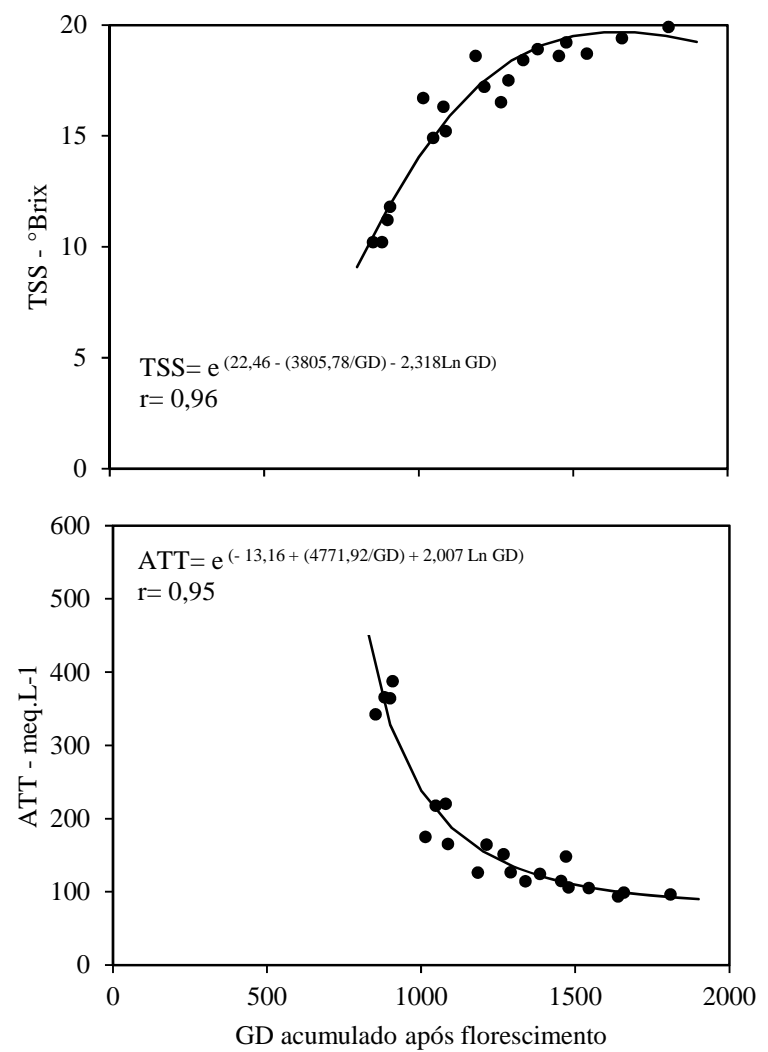

Figura 3. Relação entre teor de sólidos solúveis (TSS) e acidez total (ATT) e graus-dia acumulados após a data de floração para a 'Cabernet Sauvignon’ em São Roque (SP)

Relation of 'Cabernet Sauvignon' soluble solids (TSS) and titratable acidity (ATT) to growing degree-days accumulated from the flowering date at São Roque, São Paulo State, Brazil. 
Coeficientes das equações de estimativa de TSS e de ATT em função dos graus-dia acumulados a partir da floração e coeficientes de correlação para a ‘Cabernet Sauvignon' em São Roque (SP).

Coefficients of the equations to estimated TSS and ATT based on growing degree-days accumulated from the flowering date and correlation coefficients for the 'Cabernet Sauvignon' at São Roque, São Paulo State, Brazil.

\begin{tabular}{|c|c|c|c|c|}
\hline \multirow[b]{2}{*}{$\begin{array}{c}\text { Parâmetro a ser } \\
\text { estimado }\end{array}$} & \multicolumn{3}{|c|}{ Coeficientes da equação } & \multirow[b]{2}{*}{$\begin{array}{l}\text { Coeficiente de } \\
\text { correlação (r) }\end{array}$} \\
\hline & $\mathbf{a}$ & b & c & \\
\hline TSS ( ${ }^{\circ}$ Brix) & 22,46 & $-3805,78$ & $-2,318$ & 0,96 \\
\hline ATT (meq. L $^{-1}$ ) & $-13,616$ & 4771,92 & 2,007 & 0,95 \\
\hline
\end{tabular}

\section{CONCLUSÕES}

Nas condições climáticas da safra de verão do município de São Roque, SP, pode-se concluir que, para a cultivar Cabernet Sauvignon: a) é possível seu cultivo com produtividade adequada e dentro de padrões mínimos de maturação para produção de vinho; b) os meses de agosto e setembro são os mais favoráveis à poda, quando se leva em consideração, conjuntamente, a produtividade e a qualidade do mosto; c) a estimativa do teor de sólidos solúveis pode ser feita por meio da acumulação de graus-dia a partir da data de floração.

\section{AGRADECIMENTOS}

Os autores agradecem a Vinícola Góes localizada no município de São Roque (SP) pelas facilidades oferecidas durante o desenvolvimento deste trabalho.

\section{REFERÊNCIAS}

Bates T.R., Dunst R.M., Joy P., 2002. Seasonal dry matter, starch, and nutrient distribution in 'Concord' grapevine roots. HortScience, 37, 313-316, 2002.

Borghesan M., Gavioli O., Pit F.A., Silva A.L., 2011. Comportamento vegetativo e produtivo da videira e composição da uva em São Joaquim, SC. Pesquisa Agropecuária Brasileira, 46, 398-405.

Brighenti A.F., Rufato L., Kretzchmark A.A., Schlemper C.,2011. Desempenho vitivinícola da Cabernet Sauvignon sobre diferentes porta-enxertos em região de altitude de Santa Catarina. Revista Brasileira de Fruticultura,33, 96-102.

Detoni A.M., Clemente E., Fornari C.,2007. Produtividade e qualidade da uva 'Cabernet Sauvignon' produzida sob cobertura de plástico em cultivo orgânico. Revista Brasileira de Fruticultura, 29, 530-534.

Ferreira M.A., Pedro Júnior M.J., Santos A.O., Hernandes J.L., 2004. Modificação parcial do ambiente de cultivo da videira
'Cabernet Sauvignon' sobre diferentes porta-enxertos: efeito sobre a produção e o teor de sólidos solúveis. Bragantia, 63, 439-445.

Giovannini E.,1999. Produção de uvas para vinho, suco e mesa. 364 p. Renascença, Porto Alegre.

Hidalgo L., 2002. Tratado de viticultura general. 1235 p. MundiPrensa Ed., Madrid.

Jubileu B.S., Sato A.J., Roberto S.R., 2010. Caracterização fenológica e produtiva das videiras 'Cabernet Sauvignon' e 'Alicante’ (Vitis vinifera L.) produzidas fora de época, no norte do Paraná. Revista Brasileira de Fruticultura, 32, 451-462.

Manfroi L., Miele A, Rizzon L.A., Barradas C.I.N., Souza P.V.D., 2004. Evolução da maturação da uva Cabernet Franc conduzida no sistema lira aberta. Ciência e Agrotecnologia, 28, 306-313.

Mota C.S., Amarante C.V.T., Santos H.P., Zanardi O.Z., 2008. Comportamento vegetativo e produtivo de videiras 'Cabernet Sauvignon’ cultivadas sob cobertura plástica. Revista Brasileira de Fruticultura, 30, 148-153.

Mota R.S., Silva C.P.C., Favero A.C., Purgatto E., Shiga T.M., Regina M.A., 2010. Composição físico-química de uvas para vinho fino em ciclos de verão e inverno. Revista Brasileira de Fruticultura, 32, 1127-1137.

Orlando T.G.S., Pedro Júnior M.J., Santos A.O., Hernandes J.L. 2008. Comportamento das cultivares Cabernet Sauvignon e Syrah em diferentes porta- enxertos. Ciência e Agrotecnologia, 32, 749755.

Regina M.A., Mota R.V., Favero A.C., Shiga T.M., Silva L.H.J., Souza W.C., Novelli F.A.D., Souza C.R., 2011. Caracterização físico-química de uvas viníferas cultivadas em dupla-poda no nordeste do estado de São Paulo. Revista Brasileira de Viticultura e Enologia, 3, 84-92.

Rizzon L.A., Miele A., 2002. Avaliação da cv. Cabernet Sauvignon para elaboração de vinho tinto. Ciência e Tecnologia de Alimentos, 22, 192-198.

Sato A.J., Jubileu B.S., Assis A.M., Roberto S.R., 2011. Fenologia, produção e composição do mosto da 'Cabernet Sauvignon' e 'Tannat' em clima subtropical. Revista Brasileira de Fruticultura, 33, 491-499.

Verdi A.V., Otani M.N., Maia M.L., Fredo C.E., Oliveira A.L.R., Hernandes J.L., 2011. Panorama da vitivinicultura paulista, Censo 2009. Informações Econômicas, 41, 5-20. 